\title{
Adapting SBIRT for Batterer Intervention Program groups using motivational approaches
}

\author{
Enid Watson ${ }^{1 *}$, Carol D Girard ${ }^{2}$ \\ From INEBRIA 12th Congress, \\ Atlanta, GA, USA. 24-25 September 2015
}

\section{Background}

To present a public health initiative to adapt SBIRT for Batterer Intervention Programs (BIP) using Motivational Interviewing (MI) approaches.

While studies concur that substance use is not the underlying cause of Interpersonal Violence (IPV), approximately $50 \%$ of men in BIP are reported to be using substances at unhealthy levels. The Massachusetts Department of Public Health (MDPH) initiated a pilot to address risky substance use in BIP participants, with the Institute for Health \& Recovery (IHR), providing curriculum development, training, and technical assistance.

The curriculum employs an innovative application of SBIRT designed for use in groups, allowing BIP group leaders to provide substance use health education to men in groups. Some studies indicate that MI can result in better engagement with participants than the typical directive, confrontational approaches often used with individuals involved with the criminal justice system. It uses MI strategies adapted to allow the group members to describe the benefits and costs of substance use themselves rather than a more traditional 'health education' lecture by a group leader. Validated single item screening tools, for alcohol and for other drugs, were completed in silence during the group, and open-ended questions were asked as the Brief Intervention; leaders were encouraged to ask permission before sharing information in order to give participants a greater sense of control and ownership of their place on the road to change.

\section{Conclusions}

This adaptive SBI approach was deemed successful/very successful by $85 \%$ of men $(n=215)$. Group leaders found the material/implementation relevant and useful. Adapting

\footnotetext{
* Correspondence: enidwatson@healthrecovery.org

${ }^{1}$ Institute for Health \& Recovery, USA

Full list of author information is available at the end of the article
}

SBIRT for Batterer Intervention Program (BIP) Groups Using Motivational (MI) Approaches is a low-cost, nonthreatening initiative to increase ambivalence to change amongst men who batter. Upon implementation in a second program, this curriculum will be used in BIPs across Massachusetts.

\section{Material and methods}

The workshop will include a brief, didactic overview of the curriculum, and then an interactive group experience, using materials and methodology from the curriculum, will be implemented during the session.

\section{Results}

This adaptive SBI approach was deemed successful/very successful by $85 \%$ of men $(n=215)$. Group leaders found the material/implementation relevant and useful. Further implementation in the 17 Batterer Intervention Programs across the state will ensue in 2016.

\section{Acknowledgements}

Robert Haynor, the Director of Batterer Intervention Program Services,

Division of Violence \& Injury Prevention, Massachusetts Department of Public Health, initiated this project and continues to collaborate and promote its utilization across the state. Staff at Common Purpose and EMERGE programs have participated in implementation and editing.

\section{Authors' details}

${ }^{1}$ Institute for Health \& Recovery, USA. ${ }^{2}$ Massachusetts Department of Public Health/Bureau of Substance Abuse Services, USA.

Published: 24 September 2015

\section{Reference}

1. Watson E, Girard C, Haynor R: Safety and Health through Alcohol and Drug Education (SHADE) Curriculum. Unpublished curriculum. 2015.

doi:10.1186/1940-0640-10-S2-O30

Cite this article as: Watson and Girard: Adapting SBIRT for Batterer Intervention Program groups using motivational approaches. Addiction Science \& Clinical Practice 2015 10(Suppl 2):O30.
() Biomed Central

C 2015 Watson and Girard This is an Open Access article distributed under the terms of the Creative Commons Attribution License (http://creativecommons.org/licenses/by/4.0), which permits unrestricted use, distribution, and reproduction in any medium, provided the original work is properly cited. The Creative Commons Public Domain Dedication waiver (http://creativecommons.org/ publicdomain/zero/1.0/) applies to the data made available in this article, unless otherwise stated. 